\title{
Entrüstung, eine moderne Form des Ablasshandels
}

\author{
Helge Köhler \\ Dr. med., Mitglied FMH
}

Die berufliche Entscheidungsfindung ruht auf drei Säulen. Die erste Säule beinhaltet universitäres Wissen, Studienergebnisse, Informationen aus Fortbildungen, Lehrbüchern und Fachzeitschriften. Sie ist unverzichtbar und verlässlich, bildet aber nicht die ganze Wahrheit ab. Die zweite Säule resultiert aus unseren langfristigen Erfahrungen. Sie moduliert die Entscheidungen, die auf der ersten Säule beruhen, und ist ungemein wichtig, ein entscheidender Teil der ärztlichen Kunst. Die dritte Säule ist das Ergebnis unserer kurzfristigen beruflichen Erfahrungen. Sie ist nicht ganz unproblematisch und kann die Quelle von Fehlentscheidungen sein. Wie steht es aber um die Bewertung von Dingen ausserhalb unseres Berufslebens? Wie funktionieren hier Entscheidungsfindungen und welche Motivationen könnten dahinterstecken?

\begin{abstract}
Es war schon eine Ewigkeit her, dass sich die Götter um die Belange der Menschen gekümmert haben. Zu sehr waren sie mit ihren eigenen Dingen beschäftigt, zu hoch war der Tellerrand geworden, über den sie nicht mehr hinauszublicken vermochten. Apollon stöhnte unter der Last der unzähligen Konsultationen der Olympbewohner. Er konnte das Wehklagen über die in Jahrhunderten angehäuften Beschwerden seiner Götterkollegen nicht mehr ertragen. Im Wissen um die Heilkraft der Katharsis be-
\end{abstract}

\section{Résumé}

Le processus décisionnel en contexte professionnel s'appuie sur trois socles. Le premier est constitué des connaissances universitaires, résultats des études, informations obtenues lors des formations continues, manuels et revues spécialisées. C'est certes un aspect indispensable et fiable, mais il ne représente pas pour autant toute la vérité. Le deuxième socle est le résultat de notre expérience de long terme. II a une connotation subjective et module les décisions basées sur le premier socle. II est extrêmement important et enrichit de façon décisive l'art de la médecine. Le troisième socle est issu de notre expérience professionnelle de court terme. II n'est pas sans poser problème et peut entraîner de mauvaises décisions. Qu'en est-il de notre évaluation des choses en dehors de notre vie professionnelle? Comment fonctionnent nos processus décisionnels en la matière et quelles motivations les sous-tendent éventuellement? C'est à ces questions que se propose de répondre le présent article. schloss der Olymp deshalb, wieder mal nach den Menschen zu sehen. Die Götter hofften, dass die irdischen Tragödien die himmlischen Leiden mildern könnten. Sie spekulierten, dass der Sumpf da unten das Licht hier oben wieder brillanter erscheinen liesse. So klickten sie sich, zeitgemäss per Fernwartung, in eine Szene, welche fast genauso stattgefunden hat.

\section{Die Szenerie}

Später Nachmittag in einem Aufenthaltsraum eines grossen OP-Trakts. Zwei Dutzend grün gekleideter Menschen verteilen sich wahllos auf Stühlen und Sofas. Es liegt der Duft von Kaffee und fettfreier Gemüsebrühe in der Luft, man hört das Rascheln von Zeitungen. Im hinteren Ende des Raums sitzen zwei Ärzte, die auf die Starterlaubnis zum Hinausbefördern eines neuen Erdlings warten, in kurzer Distanz eine Dreiergruppe, die offensichtlich ihr Tageswerk bereits vollbracht hat. Während der Wartephase beginnen die zwei Ärzte eine spontane Konversation.

\section{Die Szene}

Arzt 1: Wo warst du eigentlich in den letzten Ferien, hast du was mit der Familie gemacht?

Arzt 2: Ja, wir waren in Norditalien, ein gemütlicher Zeltplatz, unspektakulär, aber wunderschön. Und du? 
Arzt 1: Ach, ich wage es kaum zu erzählen, ich war in Barcelona und Paris, beide Male mit dem Flieger. Es war toll. Die spanische Frühlingssonne und das Flair von Paris, einfach umwerfend. Die Tickets waren spottbillig, aber die Umwelt, der Klimawandel! So etwas sollte man ja eigentlich nicht tun. Ich gebe zu, mein Gewissen plagt mich.

Arzt 2: Na ja, die ganze Klimadiskussion hat doch was Hysterisches, Ideologisches. Lange bevor Menschen den Planeten besiedelten, gab es doch schon Warm- und Kaltperioden. Vielleicht ist der Klimawandel gar nicht so menschengemacht, wie uns immer gepredigt wird. Ich finde, du musst dich nicht grämen, nicht selbst verurteilen wegen deiner Flugreisen.

Arzt 1 (sichtlich entrüstet): Aber mein Lieber, du kannst doch nicht die Fakten ignorieren. Die Hitze wird uns zusetzen, Millionen von Menschen werden vertrieben werden, Armut, Krankheiten, all die Folgen. Leugnest du etwa den Klimawandel?

Arzt 2 (verunsichert): Ich meine nur, dass die ganze Diskussion etwas weniger ideologisch geführt werden sollte. Weniger hochgestreckte Zeigefingen, ein nüchterner Diskurs täte dem Thema gut.

Dreiergruppe zu Arzt 2: Also, lieber Kollege, Sie können doch nicht allen Ernstes die grösste denkbare Bedrohung so bagatellisieren. Wenn alle Menschen denken würden wie Sie, dann hätten wir bald die Sahara im Seefeld.

Eine OP-Schwester erscheint in der Tür. Ihr Blick geht zu den beiden Ärzten. Sie verstehen ohne Worte die Botschaft und werden in Kürze den Erdling ans Tageslicht befördert haben. Nach vollbrachter Tat schütteln sie sich die Hände, wechseln einen kurzen Blick und jeder geht seines Weges.

\section{Epilog}

Die Götter sind ratlos. Sie schauen sich gegenseitig an und können noch nicht ganz begreifen, was sie da beobachtet haben. Die Grenze zwischen Moral und Unmoral verschwimmt, Gut und Böse changieren wie die Farbe eines Ölfilms auf dem Wasser. Die erhoffte Katharsis bleibt aus. Wieder ist es Apollon, der einen klugen Gedanken äussert. «Die Menschheit hat eine neue Form der Katharsis erschaffen", sinniert er. Sie hat sich ein Instrument konstruiert, das sie reinwäscht von Schuld. «Entrüstung», ruft er in die Runde der verblüfften Götter. "Entrüstung ist das neue Heilmittel für Beschwerden, die durch die Last der eigenen Vergehen entstehen", erklärt er seinem erhabenen Kollegium. Die Götter nicken zu- stimmend. Die Falten auf ihren Stirnen aber lassen Sorge und Zweifel an dieser Entwicklung vermuten.

In jüngerer Vergangenheit konnte man einen Artikel über den Unterschied zwischen Entrüstung und Empörung lesen. Sinngemäss charakterisierte der Autor die Empörung als ein kurzes, einem Strohfeuer ähnliches Aufbegehren. Die Gefühlsregung sei spontan, impulsiv und meist von kurzer Dauer. Empörung sei selten Ursprung für langfristige Handlungskonsequenzen, aber im Moment des Empfindens echt und uneigennützig. Entrüstung hingegen ist eine kalkulierte Bewertung einer Situation, meist mit dem Ziel, die eigene Person oder das eigene Verhalten auf ein moralisch höheres Level zu hieven und sein Gegenüber zu diskreditieren. Soweit die Ausführungen des Autors.

Entrüstung ist allgegenwärtig, oft belanglos, manchmal beleidigend und abwertend. Wer von uns hat nicht schon belehrend mit dem Kopf geschüttelt, wenn der Fahrer vor uns bei grünem Ampellicht nicht unmittelbar von der Bremse aufs Gas wechselte und somit eine völlig irrelevante Verzögerung des Strassenverkehrs bewirkte. Oder wenn uns Patienten für eine Zweitmeinung aufsuchen, besteht immer die Gefahr für Äusserungen wie: «Das sehe ich aber ganz anders, diese Untersuchung sei nutzlos, aber warum man nicht jene Untersuchung schon viel früher durchgeführt hätte, und die Therapie ...» Wir denken oder sagen dies, obwohl wir wissen, dass die Kollegin oder der Kollege an sich auch Recht hatte. Die Wahrscheinlichkeit, dass ein zweitmeinender Arzt abweichend zur Beurteilung des erstmeinenden berät, ist relativ hoch, und nicht selten ist die Zweitmeinung mit einer Prise Entrüstung gewürzt. Viel eindrücklicher verhält es sich mit den globalen Entrüstungsdebatten. Themen, bei denen die Diskriminierung zwischen Gut und Böse, zwischen ethisch und unethisch auf der Hand zu liegen scheint, eignen sich hervorragend zum Lostreten von Entrüstungslawinen. Die Klimadebatte, Donald Trump, MeToo und natürlich das Thema Flüchtlinge und Migration sind prädestiniert für heftige und ausdauernde Entrüstungswellen. Beim Beobachten dieses Phänomens fällt auf, dass die Entrüsteten nicht immer einen engen Bezug zum Objekt der Entrüstung haben. Die grossen Entrüstungsdebatten nähren sich aus dem Internet und verbreiten sich viral über die sozialen Medien. Sie imitieren Engagement, sind häufig intransparent und ersticken eine echte Diskussion mit dem geschickten Schachzug einer Diffamierung des Gegners. Diese massive Abwertung gleicht einem kalkulierten Präventivschlag, welcher den Entrüsteten von der Pflicht einer argumentativen Auseinander- 
setzung entbindet. Zum Beispiel: "Mit diesen rechtsradikalen Rassisten reden wir nicht.» Warum ist also das Phänomen der Entrüstung so attraktiv, warum ist die Schwelle, sich in eine der laufenden Entrüstungsdebatten einzuklinken, so niedrig?

In unserem täglichen Leben ist Schuld unvermeidlich. Dieser Berg wächst mit der Dauer des Lebens in schwindelnde Höhen. Das merken wir, darunter leiden wir. Nur wenige besitzen die fragwürdige Eigenschaft, unempfindlich gegen das Gefühl der Schuld zu sein. Wenn wir uns mehr mit dem Smartphone als mit unseren Kindern beschäftigen oder wenn Wohlstand das Lebensziel wird, fühlen wir uns schuldig. Wenn wir uns zu wenig bewegen und zu viel Alkohol trinken, ist schlechtes Gewissen die Folge. Sind wir zu ungeduldig oder egoistisch, entstehen Schuldgefühle. Schuldfrei zu leben ist leider illusorisch. Aber wohin mit all dieser Last? Was tun mit dem beklemmenden Gefühl, das durch den wachsenden Schuldenberg entsteht? Es gibt verschiedene Methoden, mit dieser Bedrohung umzugehen. Man wird erfinderisch und kreativ, um dem Verdikt zu entrinnen, das durch die Last der Schuld droht. Und natürlich unterliegen die Methoden im Umgang mit Schuld auch einem Modernisierungsprozess. Früher konnte man sich mit Zahlungen an den Klerus reinwaschen. Der Ablasshandel vermochte das schuldhafte Leben wieder ins Lot zu rücken. Das Klingen der Münze im Sack des Kirchlichen löschte zwar nicht die Schuld, aber konnte zumindest das subjektive Missempfinden des Schuldigen lindern. Doch die Lücke, welche die Abschaffung des Ablasshandels hinterliess, musste natürlich geschlossen werden. Die Methoden wechselten, aber das Prinzip persistiert. Der Mechanismus, dass eine Handlung oder ein Bekenntnis zu einem Thema mit hoher moralischer Relevanz und verbreitetem Interesse zur Reinwaschung oder Demarkierung vom Sündhaften dient, überdauerte die
Jahrhunderte. So funktionierte der Ablasshandel, so funktioniert es bei vielen anderen Methoden und eben auch bei der Entrüstung. Strenge Diäten, Askese oder exzessiver Sport sollen die Balance im Leben wiederherstellen. Für andere ist die brutale und gewalttätige Auslegung einer Religion der Weg zur Erlösung. Die Methode der Entrüstung ist deshalb so attraktiv, weil sie über die (sozialen) Medien Millionen erreicht. Entrüstung ist kostenlos, konfessionslos, immer verfügbar, leicht erlernbar, multikulturell, bequem und somit offenbar die perfekte Methode zur Überwindung der eigenen Schuldgefühle. Schon ein beiläufiges Lippenbekenntnis für das Klima oder gegen Donald Trump reicht, um den Punktestand auf dem eigenen Moralkonto zu erhöhen. Aber wo ist der Haken, was sind die roten Flaggen, die Unbehagen bei dieser Methode aufkommen lassen sollten?

\section{Entrüstung}

- Dient nicht der Lösung eines Missstandes, sondern zielt auf die Anhebung des eigenen Moralniveaus

- Missbraucht einen reellen oder imaginierten Missstand für egoistische Ziele

- Spaltet

- Imitiert Engagement und verhindert damit echten Einsatz

- Scheut eine Versachlichung der Diskussion

- Fürchtet das Ende der Debatte (wohin mit den ganzen Schuldzuweisungen, wenn sich das Klima plötzlich nicht mehr wandeln würde?)

Natürlich sind öffentliche Debatten über Missstände notwendig und hilfreich. Aber wahrscheinlich tut man gut daran, sich ein Sensorium für die Falle des Prinzips «Entrüstung» zu bewahren. Abrüstung bei Entrüstung, Entideologisierung und Versachlichung von Debatten sind notwendig und ausserordentlich wünschenswert. 